\title{
InTEgrating Engineering Science ANd Design: CaSe Study DEVELOPMENT FOR A First YeAR ENGINEERING SCIENCE COURSE
}

\author{
Lyndia Stacey, Andre Unger, Marios Ioannidis, and Steve Lambert \\ Faculty of Engineering, University of Waterloo, Ontario, Canada \\ lestacey, aunger, mioannidis, steve @ uwaterloo.ca
}

\begin{abstract}
There is a need in engineering education to improve the connection between design and engineering science. Students should be provided more opportunities to practice applying both science and design to a single problem in order to be better prepared for challenges they will face when they enter the workforce. For this reason, an instructor of a first year engineering science course was motivated to improve its connection to the Canadian Engineering Accreditation Board (CEAB) Attributes, specifically the Design attribute. The goal was to revise the course such that the students would be required to integrate quantitative methods that were taught during the term through the means of design. It was decided that an effective pedagogical tool that could accomplish this was a case study, since it would provide complexity and context using a real-world issue that related to several course concepts. The methodology for case development, implementation strategy, future steps, lessons learned, as well as the instructor's observations will be discussed.
\end{abstract}

Keywords: case teaching method, implementation strategy, engineering education, case development

\section{INTRODUCTION}

A case study is a description outlining the complexity and context of a real-world challenge faced by a particular decision maker [1]. Context is one of the main values a case study can offer to the classroom that a traditional lecture can often miss; it allows students to increase their depth of understanding of course material and see how engineering principles can be applied to a real world problem [2]. Case studies are only a sliver of reality, and cannot fully or accurately portray real context; however, authentic and relevant cases increase student engagement, understanding and appreciation beyond traditional lectures [2][3][4][5]. Case studies provide students a setting to practice their engineering skills [1], and require the integration of technical and non-technical aspects as well as synthesis of information, which ultimately uses higherorder thinking [6]. Cases also engage students who have difficulties connecting themselves to the engineering profession, and otherwise only have the academic setting as an indicator [6].

There have been criticisms in engineering education that the lecture method should not be the only pedagogical method used in classrooms, since there are few opportunities to reflect on learning and it does not guarantee the application of learning in practice [4]. Case-based teaching is one pedagogical method that addresses these issues. It is essentially any method that employs case studies as a learning tool. Case-based teaching inherently incorporates intercommunication between the students themselves, and the instructor: this type of environment promotes problem solving abilities, can increase the effectiveness of a course, and address more learning styles compared to traditional lectures [5][7][8]. It provides real world scenarios which actively engage students and help demonstrate the relevance of a course to the workplace [3][5]. Case-based teaching turns passive learning into active learning by directly involving students in the learning process and it enhances critical thinking by relying on real world applications [5][8].

The lecture method has been used in a first year engineering science course, Earth Engineering, at University of Waterloo by an instructor who is also a coauthor of this paper (Unger). He observed that the students were often not engaged in the course content and, more importantly, were unable to fundamentally understand key concepts or actively apply what they had learned. The instructor was motivated to enhance the course by including a design component as well as a new pedagogical method to resolve these issues. The case study was selected because it could easily be incorporated into the current course structure, it could be developed in a way to ensure key engineering science principles were applied in a design environment, and because it could bring context and relevance to the classroom atmosphere. 
This approach would also help the program address the Canadian Engineering Accreditation Board (CEAB) graduate attribute of design [9], which is typically emphasized later in the curriculum. Furthermore, this would enable generating and tracking design rubrics from this course (first year) to their final capstone design project in fourth year as part of the accreditation process.

The instructor approached Waterloo Cases in Design Engineering (WCDE), a group within the Faculty of Engineering at University of Waterloo which develops and uses case studies to enhance the engineering curriculum [2]. WCDE was developed as part of the Natural Sciences and Engineering Research Council of Canada (NSERC) Chairs in Design Engineering program. WCDE staff worked with the instructor of the first year engineering course to develop a design case study as a means to enhance the connection between engineering science and design within the course, as well as increase student engagement.

\section{COURSE CONTEXT}

Earth Engineering is required for all Environmental, Geological and Civil first year engineering students; therefore, it would have a wide impact on multiple programs and instill a new teaching style early on in students' undergraduate careers.

Table 1: Lecture topics for Earth Engineering and connections to case development

\begin{tabular}{|c|l|c|}
\hline $\begin{array}{c}\text { Week } \\
\#\end{array}$ & \multicolumn{1}{|c|}{$\begin{array}{c}\text { Lecture Topics (3 classes per } \\
\text { week, 50 min each) }\end{array}$} & $\begin{array}{c}\text { Lecture } \\
\text { Connects } \\
\text { to Case }\end{array}$ \\
\hline 1 & Introduction \& minerals & $\checkmark$ \\
\hline 2 & $\begin{array}{l}\text { Weathering, erosion, soils, soil } \\
\text { hazards \& land subsidence }\end{array}$ & $\checkmark$ \\
\hline 3 & Soils \& plate tectonics & $\checkmark$ \\
\hline 4 & $\begin{array}{l}\text { Earth surface systems, geologic } \\
\text { time \& igneous rock }\end{array}$ & \\
\hline 5 & $\begin{array}{l}\text { Sedimentary, metamorphic rocks } \\
\text { \& Term Test 1 }\end{array}$ & \\
\hline 6 & Mechanics of rock materials & $\checkmark$ \\
\hline 7 & \multicolumn{2}{|c|}{ Reading Week } \\
\hline 8 & $\begin{array}{l}\text { Geological structure \& site } \\
\text { investigation }\end{array}$ & $\checkmark$ \\
\hline 9 & Earthquakes \& Term Test 2 & $\checkmark$ \\
\hline 10 & Groundwater & $\checkmark$ \\
\hline 11 & $\begin{array}{l}\text { Mass movement, slope stability \& } \\
\text { geological hazards }\end{array}$ & \\
\hline 12 & Oil sands \& Term Test 3 \\
\hline
\end{tabular}

There are around 120 Civil and 50/25 Environmental/Geological students that attend this course in back-to-back terms every year. The lecture topics for
Earth Engineering and the respective timeline are summarized in Table 1. These topics were typically covered with a didactic approach followed by three term tests worth a total of $50 \%$ of course grades. The rest of the grades were assigned to geology labs, a final soils report and a small tutorial component. There are various topics that need to be included in Earth Engineering, many of which do not directly connect or build upon each other. This meant that the students did not effectively integrate concepts or apply course material to a practical problem in previous terms. The instructor decided that certain lecture topics could be connected (see Table 1) to an overall design component. These topics are evenly distributed throughout the year. Knowing that WCDE would assist in this endeavour, and that there are many supporting studies outlining the effectiveness of casebased teaching, a new design case study was developed for this course.

\section{METHODOLOGY}

\subsection{Motivation for Case Development}

The main motivation for case development was to push the course curriculum towards a pedagogical method where students have to take responsibility for their own learning instead of assuming that the instructor will provide the necessary knowledge [5]. By taking responsibility, students are more involved in the learning process. This directly connects to the main reasons an instructor changes teaching methods away from a traditional lecture [4]:

1. the low number of students that pass the course;

2. too many students are absent (which is progressively higher as the semester continues);

3. and the high number of drop-outs.

In this instance, absenteeism is the main reason the instructor wanted to move away from traditional lectures. Particular attention was placed on the CEAB Design Attribute because the course currently focuses on Earth material principles with a hands-on laboratory assignment, but lacks a design component. The idea was to increase student attendance at lectures since they would need to learn relevant material to successfully complete a design component which would also engage them in course material, further increasing attendance. WCDE's previous experience suggested that students could better understand the design process through the use of a case study and develop a better appreciation for course topics compared to the lecture method [10].

Instructors want to feel that their efforts are appreciated. For an instructor to observe students who 
have found genuine interest in the course content, which is reflected in their engagement and the quality of work that is produced, this can justify their effort in teaching [5]. The time put towards updating the Earth Engineering course with a design case study aimed for these results.

\subsection{Case Development Steps}

There are many aspects of a case to consider: length, case type (failure case or success case), case structure (interrupted or single problem case), the engineering content and breadth of issues, etc. Making decisions on these aspects is the role of the instructor and should be guided by their pedagogical goals and ultimately what they want their students to gain from the learning experience [3]. This includes selecting the difficulty of the case problem. Cases can be developed in a way that varies the level of difficulty for the case reader in three main areas: conceptually, analytically and by presentation. This means the case can become more difficult depending on the concepts that need to be used, the nature of the decision making task, and how the case is structured [6]. For this first year class, both WCDE and the instructor chose a simple case for presentation and analysis, and developed a moderate conceptual challenge since the students only have high school experience as a foundation. This means that the students would not have a lot of exposure to open-ended problems or inductive teaching styles.

The two main learning objectives for the case study were for students to take responsibility for and validate their laboratory results, as well as apply concepts taught in the classroom to an open-ended, real-world design. By accomplishing these two objectives, students would be provided an additional opportunity to apply engineering science and design.
Three main steps were taken by the instructor and WCDE to complete case development, see Fig. 1. The first step was to analyze the course and determine which topics were appropriate for a case study. The instructor selected the course topics that could be reasonably integrated into a single case. These selected topics, as well as the two learning objectives, were established first to ensure that the final case study would fit in well with the course curriculum.

After this was completed, the second step was to search for an authentic source and gather information to create a case problem. It was preferable that the design problem would reflect a current, local, and relevant real-world problem that incorporated soil properties, groundwater and site investigation. The design of an earth dike could easily include all of these topics, and the Grand River Conservation Authority (GRCA) was approached since they recently had flooding problems along the Grand River, a body of water local to Waterloo. The GRCA agreed that an extension to the dikes near Water Street in Cambridge could provide a feasible solution. The contact at GRCA was kind enough to provide specific data that students would need to successfully design an earth dike for this section along the Grand River. Further information was gathered from public sources and from internal resources.

Once all necessary information was gathered, the case study itself was drafted. A case assignment was also created as a separate document. These two documents were reviewed internally by WCDE, by the instructor for case-course match, and by the GRCA for accuracy. The flow of case study concepts is provided in the case assignment (Fig. 2). Besides providing guidance to the students, the flow diagram of concepts also emphasized the case-course match.

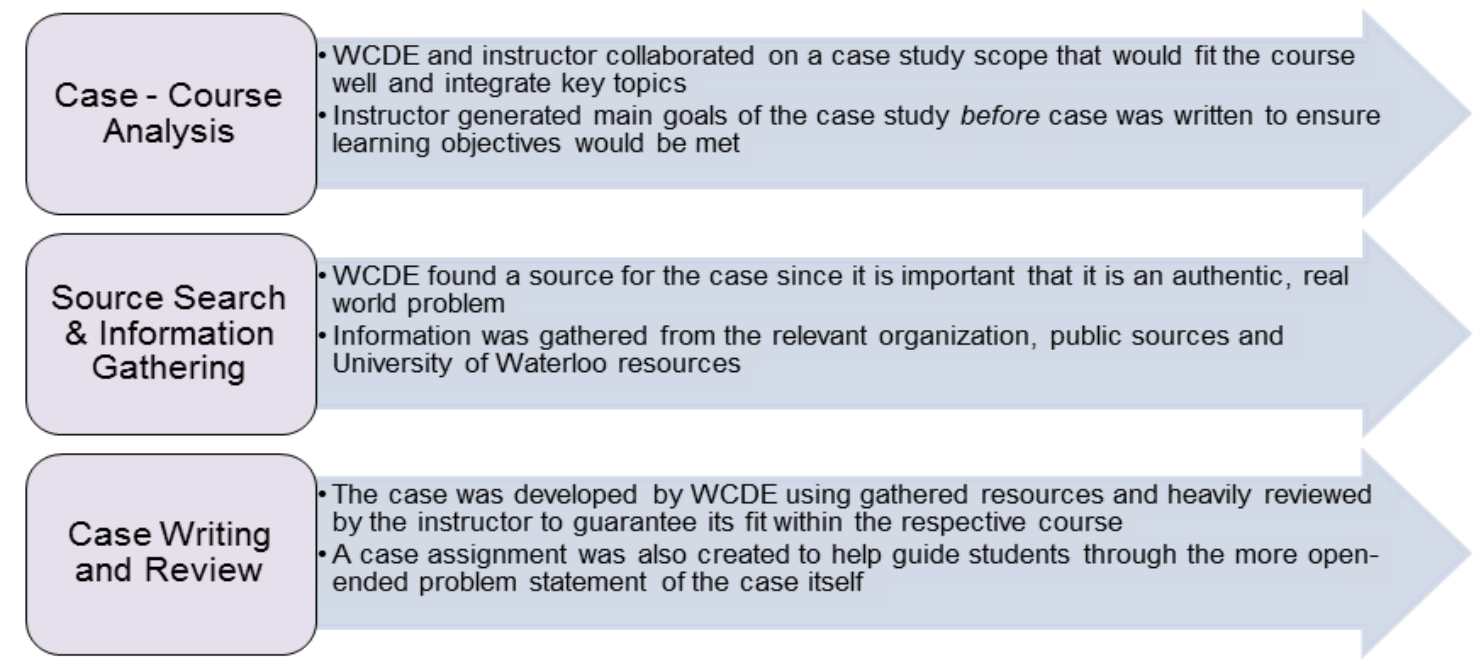

Fig. 1. Three main steps taken by instructor and WCDE to reach final case study product. 


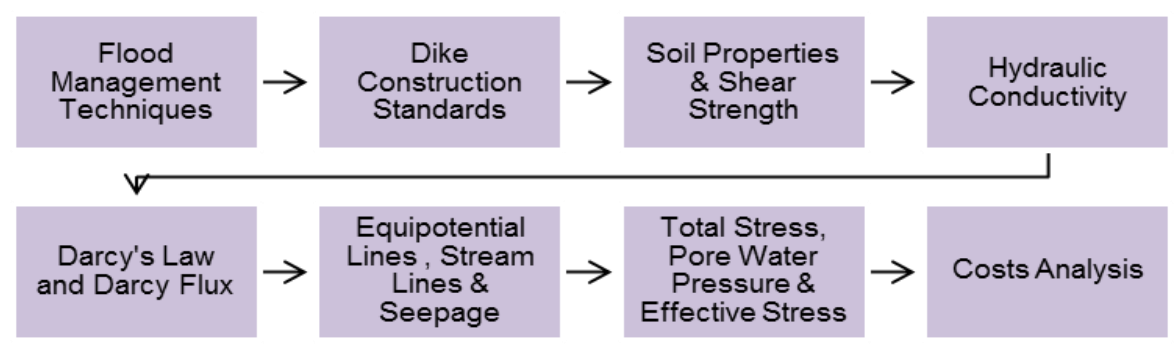

Fig. 2. Flow of case study concepts.

\section{RESULTS}

\subsection{The Case Study and Case Assignment}

The case study has an introduction that briefly outlines the scope, includes a photo of Water St. from a recent flood and provides motivation for the case problem. Background information on flood management in Cambridge as well as further details on Water St. is given for necessary context. This is followed by an open-ended problem statement outlining the need for an earth dike design as a potential solution to Water St. flooding.

There are also five appendices: a map of the Grand River, locations of river stations, elevation and flow data, proposed location of diking system extension, a crosssection of an earthen dike and unit costs for this type of project. The case assignment outlines nine steps (in further detail) that the students need to complete:

1. Review appropriate design standards. Relevant documents from various government agencies are provided. The intent is to get students to develop a preliminary scope of work when conducting unfamiliar work within the domain of their profession.

2. Estimate flood frequency, river stage, and corresponding dike dimensions. The intent is to get students to complete a preliminary design. The case assignment provides guidance for students to work through the problem like a bid to meet a tender. The case assignment specifies an earthen dike, but is open to more expensive options based on increased levels of flood protection. This step requires students to understand frequency-magnitude plots of natural perils, and their impact on engineering design.

3. Select and analyze materials. The proposed earthen dike is constrained to be homogenous material to simplify its design. However, the students must be aware of toe drains, rip-rap, and other materials to be used in its design.

4. Select an appropriate soil for the dike from sieve, hydrometer, and Atterburg limits soils labs. The students are instructed to pool their soils data from their labs, and select the best candidate to be used for the homogenous fill. The premise mimics the steps of having to select from multiple vendors of aggregates.

5. Calculate total stress within the dike. The students are instructed to use their knowledge of lithostatic stress to determine the total stress at various points within the dike. The water table is established using the Dupuit assumption. Mass densities of unsaturated and saturated soils are obtained from their lab reports. This step integrates lecture material from other first year courses (Mechanics 1 and 2) as well as properties of soils (Unified Soils Classification System).

6. Estimate hydraulic conductivity of the soil based on Unified Soil Classification analysis of lab data. The passing curve is used to calculate $\mathrm{d}_{60}$, $d_{30}$ and $d_{10}$ values that can be used in empirical relationships to estimate the hydraulic conductivity of the soil. This step integrates material from solid and fluid mechanics (groundwater) lectures, week 10 in Table 1. It also requires students to review papers, and select an appropriate relationship with minimal guidance.

7. Estimate seepage through dike using Darcy's law. Simple flow lines are drawn for the water table and along the base of the dike, extending to the toe drain. The upstream and downstream potential lines are drawn next. Finally, the students use Darcy's law to calculate a preliminary flux and total discharge based on the cross sectional area open to flow. Care is taken to ensure students understand that this is not a flow net analysis, which is covered in Geotechnical Engineering 1 (a third year course). This step integrates (groundwater) fluid mechanics lectures, with an emphasis on fluid potential, and Darcy's equation.

8. Calculate pore-water pressure assuming water is hydrostatic, and then calculate effective stress within the dike. Slope stability calculations are 
not required since this material is outside the scope of the course (it is covered three terms later in Geotechnical Engineering 1).

9. Estimate volume and cost of materials, as well as cost of construction based on a table of unit costs provided to the students. The students are encouraged to contact local contractors to revise these costs. These costs re-appear in the Geotechnical Engineering 1 course in the third year of their undergraduate studies.

The flow diagram in Fig. 2 was referenced in each of the nine steps for students to connect the requirements to relevant class concepts.

\subsection{Intended Implementation Strategy}

Case implementation plays a vital role in success [3]. The implementation strategy for the Earth Engineering case study was based on simplicity and minimizing the impact on the existing structure of the course. The order and content of the lectures were not changed. The case study was provided to the students in week 3 (of 13) of the semester along with a brief explanation of its connection to the course, including details on the work students would be required to complete throughout the term. This included using results from a detailed soils report based on lab sessions and applying these results to the case. The instructor was able to point out concepts throughout the semester so that students could make a note of these connections to the case study.

After being introduced in week 3 , the case was given a low priority until week 10 of the term, at which point the case assignment was officially assigned to the students. This was done during tutorial sessions where the large class size (123 students) was broken into 2 groups. During these sessions, the instructor discussed the case details and expectations. The students were asked to work in groups of 6 to complete the case study problem and hand in a formal report at the end of the term which addressed the design concepts provided to them in the case assignment. The structure of the case assignment is outlined in Fig. 2.

It was expected that students split the work of the design on their own within their groups and refer to the case assignment, lecture notes, as well as notes from the tutorial session to complete work independently. The instructor was available for clarification and guidance, but the students would have to apply concepts to an openended problem without direct instructions. All relevant lectures had already been given along with three term tests so the students were expected to be well-versed in the course material and ready to apply this theory to the earth dike design.

\subsection{Actual Implementation}

When implemented in the Winter 2015 term, students showed limited interest when the case study was first introduced; they did not look into the details of the case or ask many questions, presumably because the deliverable was much later in the term and it was not considered a priority. Once the case study was formally assigned to the students in week 10, there was considerable pushback. Students did not feel prepared to complete the case study since they were overwhelmed with other course deliverables; their soils report was also due near the end of the semester (a few weeks before the case study was due). This gave them too small of a window to complete the case since they needed solutions from the soils report for their earth dike design. The class representatives approached the instructor to request that the case study assignment be dropped as a formal requirement. The instructor agreed, wanting them to focus on their soils report, not wanting to cause further stress to the first year students at the end of the term (considering it was only 1 of their 5 courses), and because he did not want to have students associate a negative experience with the case method early on in their undergraduate career.

\section{DISCUSSION}

When a curriculum is redesigned, the student workload must be considered which includes private studies, assignments, labs, lectures, etc. This is important from the instructor's perspective because an excessive workload at any point in the term interferes with sufficient application of concepts, which means students will not understand everything properly [4]. When the case study was officially assigned, students were already working on another large project for the course. If the timing of these two assignments had been more spread out as part of the implementation method, this may have reduced student stress related to workload, resulting in their ability and willingness to apply the course material to a design. There is also typically a higher workload on students at the end of term as a cumulative result of all their courses, so implementing the case study earlier in the term may help this issue on a wider scale.

There was also student resistance to the new pedagogical technique. Instructor observations from various studies on this issue acknowledge initial resistance by students to the case method because they are not used to more open-ended problems where they need to make their own decisions in an analytical or design environment [3]. Therefore, it is especially important to gradually introduce the case method to first year students (either by case complexity, case expectations, case guidance, workload, etc.) since high school usually enforces that 
learning comes from direct instruction. Students often focus on the ratio of work load to grades [3]. For Earth Engineering, they needed more time to get conceptually organized since they were attempting a new learning process and, therefore, the implementation required a more organized approach [5].

Problems arise when too much time is dedicated to theoretical knowledge and not enough time is provided for application and practical operation [4][8]. Although including a case study in Earth Engineering addresses this problem, the integration of the case study will need to be more intricate and the course structure will have to be redesigned. The efforts made during case development to align case content, scope and the problem statement with the course objectives were deemed successful; however, these benefits were not realized without equal effort on an effective implementation strategy that catered to first year students and first time exposure to the case method.

Based on the student feedback and instructor observations, an extensive analysis of the implementation strategy and course structure for Earth Engineering was conducted. The case method requires the instructor to take on a "guide" role [8]. This proved challenging for the instructor since the students felt overwhelmed by the open-ended case problem and wanted clear steps on how to design the earth dike.

It was felt that students should have an inquiry-based and open forum to problem solve instead of entirely step by step instruction [5]. This means that the instructor must provide more guidance to the students so they feel capable of successfully completing their first case study without being provided detailed instructions. This may be accomplished through better scaffolding, by using assignments throughout the term that force students to analyze the case problem in steps, which ultimately guide them through the design process [3].

A standard case implementation often includes individual reading, class introduction to the case, small group discussion, assignments and a closing class discussion. More effort will be made to include these aspects in a more structured way since this has been proven effective [1][3]. This would break up the case problem for the students and have them reflect on the problem at multiple levels (individual, small group, full class). This also walks them through the case method more thoroughly since most first year engineering students are unfamiliar with this learning style and need support to develop learning strategies. It is also clear that more time needs to be dedicated to the case.

Spacing out case activities and slowly introducing different aspects of the problem is called an "interrupted case"; it is a more supportive strategy [10]. The instructor has the opportunity to point out connections with course material and fully emphasize the application of concepts in the case study [3]. First year students cannot make these connections on their own, especially given the high workload of this course and the program. In the next offering, lecture time will be dedicated throughout the term to discuss components of the case study and emphasize how these aspects are directly applying theory taught in previous lectures to the case study.

Design case study implementations indicate that students appreciate time for discussions between other students and the instructor in order to understand the problem better [10]. This was attempted by including a single case study tutorial but needs to be more frequent and earlier to have greater impact. A case implementation broken up into multiple class activities and assignments is successful in increasing student interest and understanding in course material over the lecture method [6]. Implementation should be structured in a way that forces students to understand the case problem and brainstorm potential solutions independently [6][10]. Students will need the incentive of grades to put effort towards the various case deliverables. Therefore, grades will be assigned for each step of the case as well as for their final design. Consideration is currently being made on what component of the course will need to be removed in order to accommodate the case study and balance the workload.

In the next implementation, students will be asked to actively reflect on their learning [6][10]. This is a valuable learning tool that is not often used in engineering education [8]. Students may not be fully aware of how many course concepts they used throughout the case or that they have gone through the design process. It will be the role of the instructor to offer insights on the important conclusions and solutions to ensure students come to this realization.

\subsection{Recommendations}

With regards to the case introduction, a greater emphasis on explaining the context of the case itself and also the case method should be employed. Since this is a first year course, expectations on the students' ability to solve open-ended problems and learn from a new teaching style must be lowered and more guidance will be provided. It is recommended, especially for case studies introduced early in an undergraduate program, to help students synthesize engineering principles they learned in the course [6] so this foundation will carry forward in their undergraduate career. Future courses can increase expectations and reduce guidance since there has already been exposure to the case method. The Earth Engineering course, however, will have to treat the case study as an introductory experience. Additions or changes to the case study will be made to ensure its structure matches changes in implementation. An example of this could be the addition of multimedia. Even though there are pictures included in the case study that help visualize the case 
problem for the students, it would be beneficial to have a video of this site or conduct a small field trip to the specific area since it is close to the university.

It is highly recommended that the instructor pushes their students to analyze, question, argue and reflect on the case problem and to propose solutions based on theories taught in class [4][8]. This will require more deliverables and time on the case study, and means that the instructor translates the meaningfulness (engagement and interest) into thoughtfulness (conceptual understanding) for the students [3]. It is also important to properly assess student learning and their attitude towards the selected case study and implementation strategy for the next cohort. This will help to measure success and failures while promoting continuous improvement [3].

\section{CONCLUSION}

An engineering design case study for the first year Earth Engineering science course was developed. The case integrated key course concepts and helped address the CEAB Design attribute [9]. Although the initial implementation was not successfully completed, the value of the developed case study and the case teaching method were both recognized. A second effort using a refined implementation strategy will be attempted for the next course offering using the student feedback and instructor observations.

\section{Acknowledgements}

The authors would like to thank the Grand River Conservation Authority for supporting the development of this case study.

\section{References}

[1] Louise Maufette-Leenders, James Erskine, and Michiel Leenders, Learning with Cases. London, ON: Ivey Publishing, 2007 ( $4^{\text {th }}$ ed.), 120 pp.

[2] Steve Lambert, "Sustainable design throughout the curriculum using case studies," Int. J. Engng Ed, vol. 26, no. 2, pp. 401-407, 2010.

[3] Aman Yadav, Gregory M. Shaver, and Peter Meckl, "Lessons learned: Implementing the case teaching method in a mechanical engineering course," Journal of Engineering Education, vol. 99, no. 1, pp 55 - 69, January 2013.
[4] José-Reyes Ruiz-Gallardo, et al., "Assessing student workload in Problem Based Learning: Relationships among teaching method, student workload and achievement," Teaching and Teacher Education (2010), doi:10.1016/j.tate.2010.11.001

[5] Stephanie Luster-Teasley and Cindy Waters, "Reforming environmental engineering laboratories for sustainable engineering: Incorporating problem based learning and case studies into an environmental engineering lab course," in Proc. ASEE American Society for Engineering Education Conf., (Vancouver, BC; 26-29 June 2011), 12 pp., 2011.

[6] James E. Lewis and Norb Delatte, "Implementation and assessment of a failure case study in a multidiscipline freshman introduction to engineering course," in Proc. ASEE American Society for Engineering Education Conf., (Indianapolis, IN; 15 18 June 2014), 10 pp., 2014.

[7] Richard Hake, "Interactive engagement versus traditional methods: A six-thousand-student survey of mechanics test data for introductory physics courses," American Journal of Physics, vol. 66, no. 1, pp. 6474, January 1998.

[8] Xiaoming Sheng and Xuewu Hu, "Teaching method reform of the hydraulic and pneumatic course based on engineering application cases," in IEEE Workshop on Advanced Research and Technology in Industry Applications Conf., (Ottawa, ON: 29-30 Sept. 2014), 4 pp., 2014.

[9] Engineers Canada, "Accreditation criteria and procedures report 2014," Available as of April 9, 2015 from https://www.engineerscanada.ca/accreditationresources.

[10] Oscar Nespoli, William Owen, Colin Campbell, and Steve Lambert, "Engineering case study implementation: Observations, results and perspectives," in Proc. ASEE American Society for Engineering Education Conf., (Austin, TX; 14-17 June 2009), 12 pp., 2009. 